\title{
Research and Practice of Establishing Long Term School-Enterprise Collaboration
}

\author{
Xiyu Pang \\ Information science and electrical engineering dept. \\ shan dong jiao tong university \\ Jinan, China \\ wangcheng_1001@163.com
}

\begin{abstract}
In recent years, school-enterprise collaboration has been a typical talents cultivation model in colleges and universities. However, there are prominent problems in practice. It is a key issue for universities, enterprises and the government as to how to solve key problems and promote the positive development of school-enterprise collaboration. Modern information technology has the features of "long distance, openness, multi-media, and being networked". Applying information technology into school-enterprise collaboration could solve the problems in school-enterprise collaboration, and promote the sustainable development of school-enterprise collaboration. This paper offers the plan of applying information technology into long term school-enterprise collaboration in Shandong Jiao Tong University, and it has made favorable results in the primary practice.
\end{abstract}

Keywords-school; enterprise; job; collaboration

\section{INTRODUCTION}

In the process of work-study combination and internship of school-enterprise collaboration, a lot of colleges and universities met a series of prominent problems:

The students' work efforts do not match their knowledge. During their intern, besides work, the students should finish their study. Yet, their workload is heavy in the enterprises. There is difficulty for the teachers to accomplish face-to-face teaching, and the universities emphasize employment rate, which would often overlook the students' study. Although students cultivated in this model, after graduation, have work competence, their adaptability is relatively narrow, and their thought is limited. They could not understand the relation between their knowledge, and lack the ability to think and deal with problems with an even broader view, which represents in their lack of strength[1,2].

There exists a disparity between the students' expected job and reality. At present, most of the students are single children from well-off families, and they lack hard-working spirit and independence, and they could not adjust themselves to their role during internship. They should switch from a student to an employee, and obey the discipline both at work and in the university. Generally speaking, since they have insufficient experience, they do not tend to accept the management model in the enterprises[3]. They would deem as college students who have received higher education, they are skilled students with high theoretical level. However, the enterprises exert strict management and requirements of the employees. The students have grand plans but little skill, and could not adapt to the working concept of "high yields and accomplishment, paid by the piece, and count the workload by products.” Besides, there is a disparity between their expected salary and their actual payment. For the above reasons, the students during internship tend to be sullen and would often complain, and in severe cases, the students would lose confidence[4].

There is difficulty to guide and supervise the students during their internship. The students often do their intern in different enterprises and posts. Since their intern lasts for a long time and their intern places are dispersed, the teachers could not guide and supervise the students if they do not go to their intern places, which make management and tracking complex and difficult.

It is crucial for the universities, enterprises and the government to solve key problems and promote the sound development of school-enterprise collaboration. Modern information technology has the features of "long distance, openness, multi-media, and being networked", and under its support, we can establish long term school-enterprise collaboration, solve the above problems and promote sustainable development of school-enterprise collaboration.

\section{MEASURES TO BE TAKEN}

Under the support of information technology, as to how to establish long term school-enterprise collaboration, the research scheme of Shandong Jiao Tong University includes the following aspects:

(1) Optimize course system and reduce the difficulty of study during the students' intern. Keeping market-oriented and based on the company's survey, Supervision Committee of leading experts and entrepreneurs shall optimize the course system. In the setting of the curriculum, we should take both basic courses and special courses into consideration. So far, on one hand, catering to the need of the market, some universities reduce basic courses and replace them with lots of special courses, which results in lack of theoretical knowledge for short of classes. The students do not have a complete theoretical knowledge system, which affects the study of special technology courses later on. On the other hand, certain universities emphasize basic courses instead of special courses, especially the practice, which results in that the students do not meet the requirements of the enterprises when they graduate. In 
the premise of linking the courses in sequence, we put the difficult courses in the first six semesters, and reduce the students' burden in study during their intern in the fourth year.

(2) Impose rules and regulations, and establish buffering mechanism for the students to adapt to the intern environment.

Only with restraints there are regulations, and only with regulations there is sound development of school-enterprise collaboration. In order to ensure long term school-enterprise collaboration, we should first formulate rules and regulation, and analyze the interests of the students and the enterprises. With dialogue with the enterprises, we should define the responsibilities, rights and interests of the enterprises and universities; in the meanwhile, we should avoid overemployment during their intern, and provide protective mechanism for the students to adapt to the intern environment and guarantee study time during their intern.

(3) Establish protective mechanism to guarantee the student's study during their intern with the application of information technology.

As an important link in the teaching process, intern is a crucial method to cultivate the students' practical ability and is a crucial measure for the students to fulfill their job. Yet, we should adopt effective measures to guarantee that their study is accomplished with high quality and quantity, and the students shall have a complete knowledge network, providing momentum for their sustainable development in their career life. Since their intern lasts for a long time and their intern places distribute in different areas, the teachers could not give face-toface lectures. If the employees in the enterprises offer lectures, it will add the costs of the enterprises, and could not guarantee the quality of theoretical courses; If all by the students' selfstudy, it could by no means guarantee the quality.

The fast development of information technology makes it possible to give decentralized long-distance interactive video lectures. Real time interactive situational teaching system is a system software which offers real time teaching service. It adopts telephone conference system and video interactive system, providing a convenient and real time interactive tool for the students and teachers. It extends traditional classes to the Internet, breaks through the concept of traditional classroom, which combines the teachers and students. Real time interactive situational teaching system represent the advanced computer science and technology, but also employs high quality teaching resources to the greatest extend. The characteristics of the system are: with the interactive method of multi-media network teaching, it gives traditional teaching by means of long distance simulation. Besides, it is easy to operate the system with low cost. By giving initial investment, we can use the system for a long time, which guarantees its economic feasibility.

The students can finish their learning of theoretical courses through real time interactive situation teaching system during their intern. For the trials of corresponding theoretical courses, they can do it under the guidance of the employees in the company, since the employees have rich experience.

Make track and offer guidance and management to the students' intern with information technology.
Since the intern lasts a long time, and the intern places distribute in different areas, the university could not dispatch many teachers to give guidance at the intern base. During years' of school-enterprise collaboration in Shandong Jiao Tong University, we sum up two effective ways to solve the problems for the management of the students during their intern.

The first manner: Intern site leader's responsibility system. We establish intern site leader's responsibility system, and the teachers take charge of the intern site's construction, schoolenterprise communication and offer guidance and management for the students during their intern. Intern site leader must be the teacher who engages in the teaching of academic courses, and have a thorough understanding of the business of the intern site and its major technology. Intern site leader should go to the enterprise for a talk with the students on a regular basis, and offer relevant guidance; besides, intern site leader can employ information technology, such as MSN, QQ, E-mail and telephone to know about the students' intern performances in a timely manner. We'd better use "Students intern management system" (it only demands a little investment) to standardize our guidance and management for the students' intern; we should ask the students to submit intern schedule and summary on a regular basis, and the intern site leader should find the problems in the students' intern, study and their psychological problems and solve the major problems in a timely manner. "Students intern management system" can track the students' performance during their intern, and make regular evaluation, and the students could give feedback to the teachers' guidance, and it offers supporting data to perfect the students' intern. In addition to the responsibility of offering guidance and management, the teachers should also offer assistance when there is recruitment in the intern base; they should communicate with technology department in the enterprises on a regular basis, make track of mainstream business and technology at present and in the recent three years, and make a survey for the making of talents cultivation plan and the revision of the syllabus; get to know recruitment plan of the intern base in the next year; make track and survey of the students who have graduated and work in the intern enterprises.

"Intern site leader's responsibility system” can achieve close connection between universities, enterprise and inter students, and promote the sustainable development of schoolenterprise collaboration.

The second manner is the combination of teachers' work in the enterprises, cooperative research and guidance to the students. Universities should establish sound teachers' training system, select teachers to work or study in the enterprises, and even for joint research programs, which will enhance the teacher's engineering background and working experience, help them master the enterprises' major business process and technology, and enlarge exchanges between the university and enterprises. During the teachers' stay in the enterprises, they should offer guidance and management for the intern students, solve emotional problems, problems at work and study in a timely manner. It can promote in-depth exchanges and communication between the enterprises, universities and intern students. 


\section{CONCLUSION}

This paper focuses on the major problems in the students' intern in school-enterprise collaboration, makes an in-depth theoretical research, and put forward a solution for the key problems. From the optimization of course system to the making of school-enterprise collaboration agreement and the standardization of rules and regulations; with the application of information technology, university teachers combine distance education and assistance in intern in the enterprises, and we combine "intern site leader's responsibility system", "teachers' work in the enterprises, joint research programs" and "offer guidance and management for the student's intern, establish indepth long term school-university collaboration, which guarantees the interests and sound development of the students, enterprises and university.

\section{ACKNOWLEDGMENT}

Shandong Province Soft Science Research Project (NO:2014RKB01930); Jinan Technology Development Soft Science Research Project (NO: 201221160);Shandong Jiao Tong University Teaching Research Project(NO:JY201308)

\section{REFERENCES}

[1] Meng xiaofeng, Ci Xiang, Large Data Management: Concepts, Technologies and Challenges [J]; Research and Development of Computer; 2013.01.

[2] [The Reform and Practice on Communication Electronic Circuit Course[A];2010 International Conference on E-Health Networking, Digital Ecosystems and Technologies Proceedings(Volume 2)[C];2010.

[3] The Research of Software Engineering Curriculum Reform[A];Proceedings of 2010 Third International Conference on Education Technology and Training(Volume 3)[C];2010.

[4] Chu Ming; [D] Research and Development of High-Tech Industry in Our Country IT knowledge Employee Ability; Tianjin University; 2008. 